\title{
Influence of Aggregate Moisture Content on the Mechanical Properties of Resin Mineral Composite
}

\author{
Jicai Yin \\ Key Laboratory of High Efficiency and Clean Mechanical \\ Manufacture, Ministry of Education of China \\ School of Mechanical Engineering, Shandong University, \\ Jinan, China \\ email:szyinjicai2008@163.com
}

\author{
Jianhua Zhang* \\ Key Laboratory of High Efficiency and Clean Mechanical \\ Manufacture, Ministry of Education of China \\ School of Mechanical Engineering, Shandong University, \\ Jinan, China \\ email:jhzhang@sdu.edu.cn
}

\author{
Yi Zhang \\ Key Laboratory of High Efficiency and Clean Mechanical \\ Manufacture, Ministry of Education of China \\ School of Mechanical Engineering, Shandong University, \\ Jinan, China \\ email: zhangyi.sdu@163.com
}

\section{Gang Li}

Key Laboratory of High Efficiency and Clean Mechanical Manufacture, Ministry of Education of China

School of Mechanical Engineering, Shandong University, Jinan, China

email:ligangsdu@foxmail.com

high-speed and high-precision machining technology, RMC has attracted more and more attention for its good vibration alleviating properties [3]. Compared with gray cast iron and welded steel, RMC has ten times the damping ratio that it can better absorb vibrations generated in the machining process, especially in high-speed and high-precision machining processes[2] [4]. However, the application of RMC is restricted by its limitation in mechanical strength, and considerable research should be done to improve its mechanical properties in order to satisfy the requirements of high-speed and high-precision machining.

The mechanical strength of fully cured RMC is highly related to its components and the interface between the resin matrix and filler [5]. Many previous studies focused on the effects of resin dosage [1] [6], fly ash [7] [8], types of the aggregates [1], mass content of aggregate [2], glass fiber [9-11], carbon fiber [9][12] and types of resin [13] on the mechanical strength of RMC. However, little information has been focused on the influences of aggregate moisture content on the mechanical strength of RMC. As the key component in RMC to bear loads, the aggregate weight of the total composite material accounts for more than $85 \%$, the physical and chemical properties of the aggregate has a significant impact on the mechanical properties of RMC [5]. Influence of aggregate moisture content on the mechanical strength of RMC was not received sufficient attention. Fontana and Reams [14] revealed that $3 \%$ of pre-existing water in aggregates reduces the compressive strength of the PC by half. Header and Mohammad [15] found that the polymer concrete's flexural strength decreased from 25.8 MPato $0.68 \mathrm{MPa}$ and compressive strength from 190MPa to 85 MPa when the initial moisture added to the aggregate content increased from $0 \%$ to $5 \%$. However, data is still scarce. We need to provide more documents. In this 
article, the effect of aggregate moisture content on the mechanical strength of RMC was investigated. Research results show that the mechanical strength of RMC deteriorated with the increasing moisture content of the aggregate.

\section{EXPERIMENTAL PROCEDURES}

\subsection{Materials}

The aggregates used in this study were granite particles produced in Jinan, China. These aggregates were classified into several different groups according to their diameters. Fly ash was used as the filler, which is a by-product from burning coals in local power plants. Epoxy resin 615A was used in this study. The stabilizer was ethylenediamine, and the flexibilizer was dibutyl phthalate (DBP). Acetone is used as the diluent to make the liquid composite less mucous.

\subsection{Measurement of aggregate moisture content}

Measurement of the water that dry out of the aggregate according to GB6284-86. In this article, granite particles are dried for 2 hours, 4 hours, 6 hours, 8 hours and 10 hours, respectively. Each experiment is measuring 5 samples, and then calculating the mean value.

\subsection{Preparation of mechanical samples of RMC}

Preparation of RMC samples composed of the composite forming process and machining process after samples are formed. Granite particles were dried for 2 hours, 4 hours, 6 hours, 8 hours and 10 hours at $105^{\circ} \mathrm{C}$ respectively before pouring molding, and then the establishment of a set of aggregate that doesn't dry as a reference. Both liquid and solid raw materials were mixed evenly, and then mixed together to set on a vibration table . The vibration frequency is $45 \mathrm{HZ}$ and amplitude is $0.25 \mathrm{~mm}$. The vibration lasted during the whole mixing process and continued for another 20 minutes after the mixing process ended.

\subsection{Preparation of mechanical samples of granite}

Granite is a kind of anisotropic inorganic composite material. In order to reduce experimental error, mechanical properties testing must be along the same direction of granite. So, granite must be marked before cutting. Granite is cut into $50 \mathrm{~mm}$ x $50 \mathrm{~mm}$ x $50 \mathrm{~mm}$ cube for compressive strength test and $160 \mathrm{~mm}$ x $40 \mathrm{~mm}$ x 40 $\mathrm{mm}$ for flexure strength test. Processing methods of the different granite moisture content are given in Table 1. Measurement of the water that granite moisture content according to GB/T 23561.5-2009.

\subsection{Measurement of resin curing degree}

Curing degree was measured on a accelerated solvent extraction apparatus (ASE 300, made in USA) and the extraction solvent is methylbenzene.
TABLE 2. PROCESSING METHODS OF THE DIFFERENT GRANITE MOISTURE CONTENT

\begin{tabular}{|c|c|c|}
\hline \multirow{2}{*}{$\begin{array}{c}\text { Processing } \\
\text { methods }\end{array}$} & \multicolumn{2}{|c|}{ Mositure content (\%) } \\
\cline { 2 - 3 } $\begin{array}{c}\text { Soak in water for } \\
24 \mathrm{~h}\end{array}$ & 0.108 & 0.095 \\
\hline $\begin{array}{c}\text { Soak in water for } \\
12 \mathrm{~h}\end{array}$ & 0.0719 & 0.0723 \\
\hline No processing & 0.0576 & 0.0555 \\
\hline $105^{\circ} \mathrm{C}$ for $3 \mathrm{~h}$ & 0.0487 & 0.0432 \\
\hline $105^{\circ} \mathrm{C}$ for $6 \mathrm{~h}$ & 0.0173 & 0.0181 \\
\hline $105^{\circ} \mathrm{C}$ for $24 \mathrm{~h}$ & 0 & 0 \\
\hline
\end{tabular}

\subsection{Mechanical properties testing}

Mechanical strength was performed on a YE-2000 hydraulic pressure test machine and the maximum pressure allowed was $2000 \mathrm{kN}$. RMC samples of $50 \mathrm{~mm} \times 50 \mathrm{~mm} \times 50 \mathrm{~mm}$ and $40 \mathrm{~mm} \times 40 \mathrm{~mm} \times 160 \mathrm{~mm}$ in dimension were prepared for uniaxial compression tests and flexural tests respectively after curing 10 days at room temperature.

\subsection{Scanning electron microscopy (SEM)}

A scanning electron microscopy imaging was obtained using JSM-6510LV (JEOL) to investigate the surfaces of RMC.

\section{RESULTS AND DISCUSSION}

\subsection{Effects of baking time on the aggregate moisture content}

TABLE 2. MEASUREMENT AND CALCULATION OF AGGREGATE MOISTURE CONTENT

\begin{tabular}{|c|c|c|c|c|c|}
\hline Baking time & $2 \mathrm{~h}$ & $4 \mathrm{~h}$ & $6 \mathrm{~h}$ & $8 \mathrm{~h}$ & $10 \mathrm{~h}$ \\
\hline $\begin{array}{c}\text { The water that } \\
\text { dry out of the } \\
\text { aggregate (\%) }\end{array}$ & 0.0576 & 0.0664 & 0.0737 & 0.0746 & 0.0739 \\
\hline
\end{tabular}

Aggregate moisture content is highly dependent on the weathering grade of aggregate [16]. Aggregate used in this paper is made of natural granite after crushing and screening, which have the same storage time and conditions. So that all aggregate have the same weathering grade and the same moisture content. The baking time and the corresponding water that dry out of the aggregate are shown in Table 2. The results of baking 6 hours, 8 hours and 10 hours are approximately equal, so that aggregate moisture content is the average of the results of baking 6 hours, 8 hours and 10 hours.

\subsection{Effects of aggregate moisture content on the mechanical properties of $R M C$}

Effects of aggregate moisture content on mechanical strength of RMC are shown in Fig.1. It is clearly shown that the compressive strength and flexural strength of RMC decreases as aggregate moisture content increases, which was attributed to the interface bond, mechanical strength of granite and curing degree of epoxy resin decreases as the aggregate moisture content increases. The compressive strength and flexure strength of RMC that aggregate moisture is zero equal to the average of the results of baking 6 hours, 8 hours and 10 hours. 


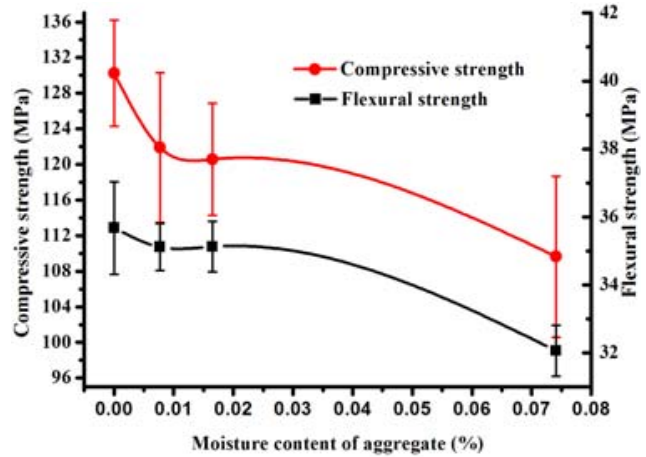

Figure1. Influence of aggregate moisture content on the mechanical strength of RMC

3.2.1 Effects of aggregate moisture content on the interface between aggregate and resin matrix

The interface between epoxy resin and granite aggregate is a weak part in RMC [5]. Failure crack under uniaxial compression is always along the interface between granite aggregates and epoxy resin. The surface of the granite aggregate is easy to infiltration by water. Moisture absorption can partly form a water film on the surface of granite aggregate, which can seriously affect adsorption effect and the adhesion strength between the aggregate and resin matrix (see Fig.2).

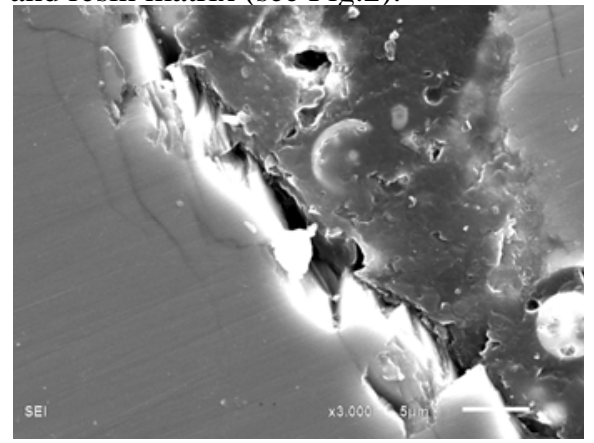

Figure 2. SEM image of interface adhesion property between matrix and aggregate

The curing process of epoxy resin is an exothermic reaction [17-21], water in granite aggregate turns into steam with the rise of temperature [15] [17]. Water vapor can adhere to the interface between aggregate and resin that it is difficult to remove in the process of vibration molding. Water vapor becomes pores after curing reaction [15](see Fig.3) , pores act as stress concentration weak points in the resin structure and result in resin failure during loading tests. The increased water content increases the number of these fatigue points, further weakening the mechanical properties of RMC.

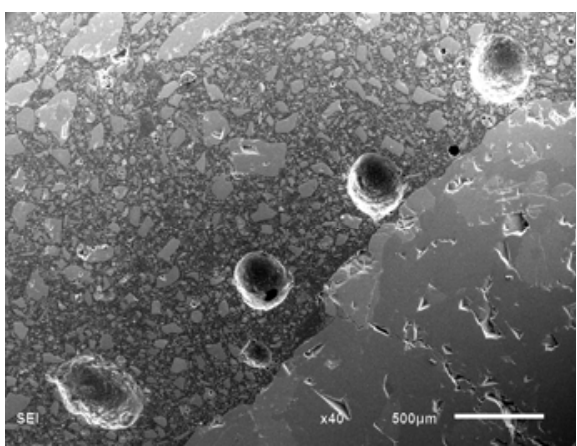

Figure 3. SEM image of visible pores near the interface

3.2.2 Effects of aggregate moisture content on the mechanical strength of granite

As the key component in resin mineral composite (RMC) to bear loads [5], the physical and chemical properties of the aggregate have an important impact on the mechanical properties of RMC. Many researchers have studied the effect of moisture content on the engineering properties of rock [21-25]. Moisture content is one of the most important factors influencing rock strength [26]. With a slight increase in moisture content may lead to a marked reduction in strength [27]. Granite aggregate moisture can weaken the adhesion strength of inside material, and reduce the uniaxial compressive strength of the aggregate. The relationship between water content and uniaxial compressive strength [18] [23] [24] could be described by an exponential equation.

$$
\sigma_{c}(w)=a e^{-b w}+c
$$

Where, $\sigma_{c}(w)$ is the uniaxial compressive strength, $w$ is the aggregate moisture content (\%), $a, b$ and $c$ are constants. The parameter $b$ is a dimensionless constant defining the rate of strength loss with increasing water content.

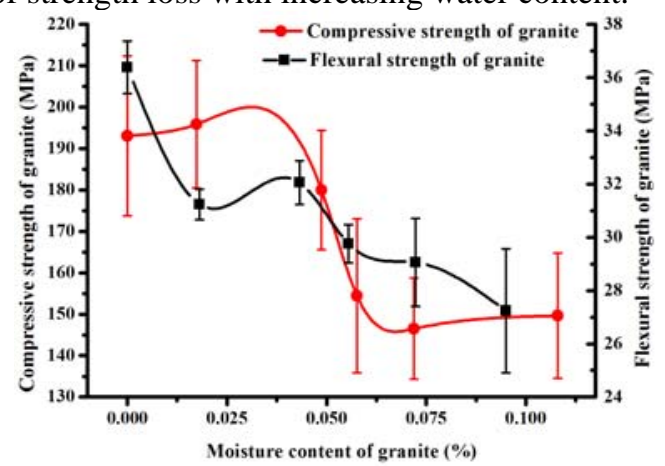

Figure 4. Effects of moisture content of granite on the mechanical strength of granite

Fig. 5 shows the fracture appearance of RMC samples after compression test. Fig.5 was taken by a digital camera, where (a) is the compressive failure samples of aggregate doesn't dry, (b), (c) and (d) are the compressive failure samples of aggregate that baking 2 hours, 4 hours and 6 hours, respectively. There are a lot of cracks across the granite aggregate in no-baking sample. Baking 2 and 4 hours samples have some cracks across the granite aggregate. Baking 6 hours sample have no crack across the granite aggregate, but only have the crack along with interface between granite aggregate and resin. 

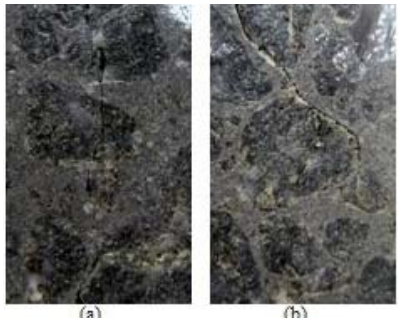

(b)
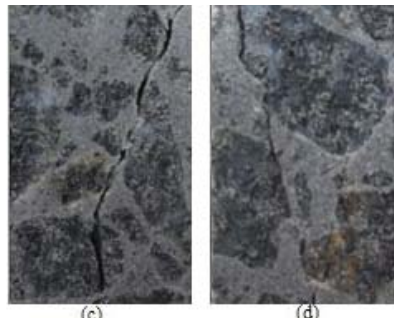

Figure 5. Fracture appearance of RMC samples after the compression test.

(a) is the compressive failure samples of aggregate don't dry, (b), (c) and (d) are the compressive failure samples of aggregate that baking 2 hours, 4 hours, 6 hours

respectively. Loading direction is from up to bottom.

\subsubsection{Effects of aggregate moisture content on epoxy} curing degree

Thermal conductivity is an important material property controlling the transport and exchange of thermal energy [28]. Aggregate moisture content has a great effect on thermal conductivity of granite aggregate. The effective thermal conductivity of granite [29] $k_{0}$ can be described by:

$$
k_{0}=n k_{f}+(1-n) k_{g}
$$

Where $n$ is fluid content of granite, $k_{f}$ is the thermal conductivity of the fluid, and $k_{g}$ is the thermal conductivity of anhydrous granite aggregate.

A similar relation can be written for the thermal conductivity of the fluid.

$$
k_{f}=r k_{w}+(1-r) k_{v}
$$

Where $k_{w}$ is the thermal conductivity of the water, $k_{v}$ is the thermal conductivity of air or void, $r$ is the water accounts for the proportion of the fluid.

The thermal conductivity of the granite aggregate with no water, the water content of the aggregate, and the air or void content of the aggregate can be described by:

$$
\begin{gathered}
k_{g}=\eta_{g} \rho_{g} c_{g} \\
k_{w}=\eta_{w} \rho_{w} c_{w} \\
k_{v}=\eta_{v} \rho_{v} c_{v}
\end{gathered}
$$

Where $\rho_{g}, \rho_{w}$, and $\rho_{v}$ is density of the granite aggregate, the water, and the air or void, respectively, $c_{g}, c_{w}$ and $c_{v}$ is specific heat of the granite aggregate, the water, and the air or void, respectively, $\eta_{g}, \eta_{w}$ and $\eta_{v}$ is the thermal diffusivity of the granite aggregate, the water, and the air or void, respectively. Under normal conditions, $\rho_{g}, \rho_{w}, \rho_{v}$, $c_{g}, c_{w}, c_{v}, \eta_{g}, \eta_{w}, \eta_{v}, k_{g}, k_{w}$ are constants, $k_{w}>k_{v}$.

Substituting (3) into (2) yields:

$$
k_{0}=n\left[k_{v}+r\left(k_{w}-k_{v}\right)\right]+(1-n) k_{g}
$$

The space that aggregate water was occupied by vacuum or air with the baking time of aggregate increases, and $r$ decreases with baking time increases accordingly. Thus, the thermal conductivity of granite aggregate increases with aggregate moisture content increases [28].

The curing process of epoxy resin is an exothermic reaction, and raise the temperature of resin curing is conducive to curing reaction. The relationship between curing rate and temperature can use the following equation.

$$
\ln \left(\frac{d \alpha}{d t}\right)=\ln (Z)-\frac{E_{a}}{R T}+n \ln (1-\alpha)
$$

Aggregate with low thermal conductivity is not conducive to dissipation of curing heat, and it is conducive to improving the curing degree and the mechanical strength of RMC will be higher [30]. Resin curing degree of different aggregate moisture content was shown in Fig.6. It is clearly shown in Fig.6 that the curing degree of resin decreases as granite moisture content increases.

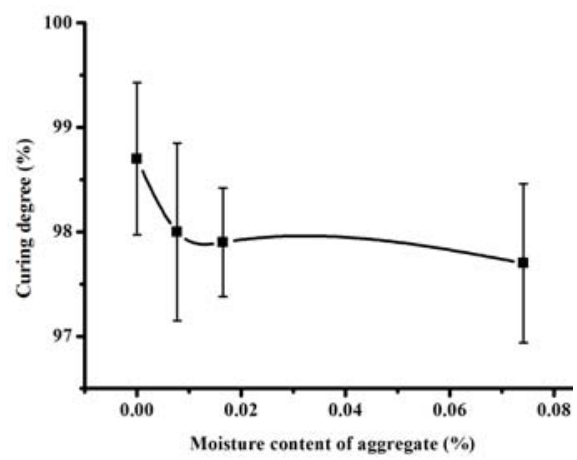

Fig.6 Effects of aggregate moisture content on curing degree of RMC

As a summary, the best mechanical strength is obtained when the baked time of aggregate at $105^{\circ} \mathrm{C}$ exceeds $6 \mathrm{~h}$. The interface wettability between resin and aggregate deteriorated with the increasing moisture content of the aggregate, and the porosity of the interface between resin and aggregate increases with the increasing moisture content of the aggregate. In addition, uniaxial compressive strength of granite and curing degree of resin decreases as the aggregate moisture content increases, which further reduced the mechanical strength of RMC.

\section{CONCLUSIONS}

Mechanical strength of RMC is highly related to the aggregate moisture content. Based on the results and discussion obtained in the present work, the following main summary remarks and conclusions can be drawn.

(1) With the increase of baking time, aggregate moisture content decreases. The aggregate moisture content is $0.0741 \%$.

(2) The interface wettability between resin and aggregate deteriorated with the increasing moisture content of the aggregate, and the porosity of the interface between resin and aggregate increases with the increasing moisture content of the aggregate.

(3) The uniaxial compressive strength, flexure strength and resin curing degree decreases with the increase of aggregate moisture content, which can further reduce the mechanical strength of RMC.

(4) Mechanical strength of RMC decreases with the increase of aggregate moisture content, the best mechanical strength is obtained when the baked time of aggregate exceeds $6 \mathrm{~h}$ at $105^{\circ} \mathrm{C}$. Compressive strength of RMC decreased from 130.25 MPato 109.65 MPa and flexural strength of RMC decreased from $35.68 \mathrm{MPa}$ to $32.07 \mathrm{MPa}$ when the aggregate content increased from $0 \%$ to $0.0741 \%$. 


\section{ACKNOWLEDGEMENT}

The work of this paper is supported by the National Natural Science Foundation of China (Grant No. 51175308) and the National Science and Technology Major Project of China (Grant No. 2012ZX04010032).

\section{REFERENCES}

[1] Header Haddad, Mohammad Al Kobaisi.Optimization of the polymer concrete uesd for manufacturing bases for precision tool machines [J].Compos Part B-Eng 2012; 43:3061-3068.

[2] Jung Do Suh•Dai Gil Lee. Design and manufacture of hybrid polymer concrete bed for high-speed CNC milling machine [J]. Int J Mech Mater Des 2008; 4:113-121.

[3] Wenfeng Bai, Jianhua Zhang, Peng Yan, Xinli Wang. Study on vibration alleviating properties of glass fiber reinforced polymer concrete through orthogonal tests [J]. Mater Design 2009;30: 1417-1421.

[4] Tao Wang, Jianhua Zhang, Shimei Hao. Damping research of fiber-reinforced resin mineral composite-based micromechanical modeling [J]. J Reinf Plast Compos 2013; 32:875-880.

[5] Tao Wang, Jianhua Zhang, Wenfeng Bai, Shimei Hao. Forming process and mechanical properties of fibers-reinforced polymer concrete [J]. J Reinf Plast Compos 2013; 32:907-911.

[6] M. Golestaneh, G. Amini, G.D. Najafpour, M. A. Beygi. Evaluation of Mechanical Strength of Epoxy Polymer Concrete with Silica Powder as Filler [J]. World Applied Sci J 2010;9(2):216-220.

[7] Jane Proszek Gorninski, Denise C. Dal Molin, Claudio S. Kazmierczak. Study of the modulus of elasticity of polymer concrete compounds and comparative assessment of polymer concrete and portland cement concrete [J]. CEMENT CONSRETE RES 2004; 34:2091 - 2095

[8] Weena Lokuge, Thiru Aravinthan. Effect of fly ash on the behaviour of polymer concrete with different types of resin [J]. MATER DESIGN 2013;51:175-181.

[9] J.M.L.Reis, A.J.M.Ferreira. Assessment of fracture properties of epoxy polymer concrete reinforced with short carbon and glass fibers [J]. CONSTR BUILD MATER 2004; 18:523-528.

[10] M.M. Shokrieh, M. Heidari-Rarani, M. Shakouri, E. Kashizadeh. Effects of thermal cycles on mechanical properties of an optimized polymer concrete [J]. CONSTR BUILD MATER 2011;25:3540-3549.

[11] Mehmet Saribiyik ,Abdullah Piskin, Ali Saribiyik. The effects of waste glass powder usage on polymer concrete properties [J]. CONSTR BUILD MATER 2013;47: 840-844.

[12] J.M.L. Reis, A.J.M. Ferreira. The effects of atmospheric exposure on the fracture properties of polymer concrete [J]. Build Environ 2006;41:262-267.

[13] Hisham Abdel-Fattah, Moetaz M. El-Hawary. Flexural behavior of polymer concrete [J].CONSTR BUILD MATER 1999;13:253-262.

[14] Fontana JJ, Reams W. The effect of moisture on the physical and durability properties methyl methacrylate polymer concrete [J]. American Concrete Institute 1985:91-104.
[15] Header Haddad, Mohammad Al Kobaisi. Influence of moisture content on the thermal and mechanical properties and curing behavior of polymeric matrix and polymer concrete composite [J]. Mater Design 2013;49: 850-856.

[16] A.Fahimifar and H.Soroush. A Moisture Index Classification System for Rocks (Mic System) [J]. Rock Mech Rock Eng 2007; 40:63-79.

[17] M.Kubisztal, G.Haneczok, A.Chrobak, A.kubik, J.Rasek. Study of epoxy resin curing process by applying internal friction technique [J]. Mater sci Eng A 2009;521-522:283-286.

[18] Diyuan Li, Louis Ngai Yuen Wong, Gang Liu, Xiaoping Zhang. Influence of water content and anisotropy on the strength and deformability of low porosity meta-sedimentary rocks under triaxial compression [J]. Eng Geol 2012;126: 46- 66.

[19] Jintao Wan, Cheng Li, Zhi-Yang Bu, Cun-Jin Xu, Bo-Geng Li, Hong Fan.A comparative study of epoxy resin cured with a linear diamine and a branched polyamine [J]. Chem Eng $J$ 2012;188:160-172.

[20] C.Garschke, P.P.Parlevliet, C.Weimer, B.L.Fox. Cure Kinetics and viscosity modelling of a high-performance epoxy resin film [J]. Polym Test 2013;32: 150-157.

[21] Jin Zhang, Hongxing Dong, Lili Tong, Lei Tong, Lei Meng, Ye Chen, Gojun Yue. Investigation of curing kinetics of sodium carboxymethyl cellulose/epoxy resin system by differential scanning calorimetry [J]. Thermochim Acta 2012;549 : 63-68.

[22] Suzana M.Cakic, Ivan S.Ristic, Vladislav M.Jaso, Radmila Z.Radicevic, Olivera Z.Ilic, Jaroslava K.B.Simendic. Investigation of the curing kinetics of alkyd-melamine-epoxy resin system [J]. Prog Org Coat 2012; 73: 415-424.

[23] B.Vasarhelyi. P.Van. Influence of water content on the strength of rock [J], Eng Geol 2006;84 :70-74.

[24] Hawkins, A.B., McConnell, B.J. Sensitivity of sandstone strength and deformability to changes in moisture content [J]. Eng Geol 1992;25: 115-130.

[25] Diyuan Li, Louis Ngai Yuen Wong, Gang Liu, Xiaoping Zhang. Influence of water content and anisotropy on the strength and deformability of low porosity meta-sedimentary rocks under triaxial compression [J]. Eng Geol 2012;126:46-66.

[26] Edy Tonnizam Mohamad, Mohamad Fauzi Md Isa, Moha For Mohd Amin, Ibrahim Komoo, Nurly Gofar, Rosli Saad. Effect of moisture content on the strength of various weathering grades of granite [J]. Elect J Geotech Eng.2011; 16:863-886.

[27] Z.A.Erguler, R.Ulusay. Water-induced variations in mechanical properties of clay-bearing rocks [J]. Int J Rock Mech Min Sci 2009;46:355-370.

[28] W.J.Cho, S.Kwon, J.W.Choi. The thermal conductivity for granite with various water contents [J], Eng Geol 2009;107:167-171.

[29] Mary P. Anderson. Heat as a Ground Water Tracer [J], Ground water 2005;43:951-968.

[30] Moetaz M.El-Hawary, Hisham Abdel-Fattah. Temperature effect on the mechanical behavior of resin concrete [J], Constr Build Mater 2000;14:317-323. 